\title{
Inhaled corticosteroids do not reduce initial high activity of matrix metalloproteinase (MMP)-9 in exhaled breath condensates of children with asthma exacerbation: a proof of concept study
}

\author{
KATARZYNA GRZELA ${ }^{l}$, WIOLETTA ZAGÓRSKA ${ }^{l}$, ALICJA KREJNER ${ }^{2}$, \\ ALEKSANDRA BANASZKIEWICZ ${ }^{3}$, MAEGORZATA LITWINIUK ${ }^{2,4,5}$, MAREK KULUS ${ }^{l}$, \\ TOMASZ GRZELA ${ }^{2}$ \\ 'Department of Paediatrics, Pneumonology and Allergology, Medical University of Warsaw, Poland \\ ${ }^{2}$ Department of Histology and Embryology, Medical University of Warsaw, Poland \\ ${ }^{3}$ Department of Paediatric Gastroenterology and Nutrition, Medical University of Warsaw, Poland \\ ${ }^{4}$ Potgraduate School of Molecular Medicine, Poland \\ ${ }^{5}$ Department of Otolaryngology, Medical University of Warsaw, Poland
}

\begin{abstract}
Inhaled corticosteroids (ICS) are the key component of asthma treatment. However, it is unclear whether they could control the activity and level of matrix metalloproteinase (MMP)-9, which is an important factor in asthma-associated inflammation and airway remodeling. Therefore, the aim of this proof of concept study was to analyze the influence of increased doses of ICS on MMP-9 in exhaled breath condensates $(E B C)$ of patients with allergic asthma exacerbation. Apart from MMP-9, the assessment concerned selected inflammation markers - exhaled nitric oxide (eNO) and cytokines (IL-8 and TNF).

The study involved a small group $(n=4)$ of individuals with asthma exacerbation. The intervention concerned increased doses of ICS with $\beta$-mimetics for 4 weeks. In addition to clinical evaluation, eNO measurements and EBC collections were done before and after 4 weeks of intense ICS treatment. The biochemical assessment of EBC concerned MMP-9, IL-8 and TNF. The data were compared to results of healthy controls $(n=6)$.

The initial levels of eNO, MMP-9 and TNF in EBC were higher in the asthma group than in controls. In all subjects IL-8 levels were below the detection limit. After 4 weeks of ICS treatment in all patients we observed improvement of clinical and laboratory parameters. Interestingly, despite reduction of eNO and TNF, the activity of MMP-9/EBC remained on the initial level.

Practical relevance of our results is limited by a small group. Nevertheless, our data suggest that ICS, although sufficient to control symptoms and inflammatory markers, may be ineffective to reduce $M M P-9 / E B C$ activity in asthma exacerbation and, possibly, airway remodeling.
\end{abstract}

Key words: asthma exacerbation, exhaled breath condensate, inhaled corticosteroids, MMP-9.

(Cent Eur J Immunol 2016; 41 (2): 221-227)

\section{Introduction}

The inhaled corticosteroids (ICS) are widely used as a basic regimen of pharmacological treatment in asthma [1-4]. The main goal of their use is to attenuate an inflammatory reaction within the respiratory tract. However, ICS are also supposed to protect from airway remodeling in chronic inflammatory diseases, especially in asthma and chronic obstructive pulmonary disease [5, 6]. Among various factors involved in both, inflammation and airway remodeling, are matrix metalloproteinases (MMPs), mainly MMP-9 [7-10].

It has been proven that patients with asthma, when compared to healthy controls, revealed increased concen-

Correspondence: Tomasz Grzela, Department of Histology and Embryology, Medical University of Warsaw, Chałubińskiego 5, 02-004 Warsaw, Poland, e-mail: tomekgrzela@gmail.com Submitted: 27.10.2015, Accepted: 7.03.2016 
tration and activity of MMP-9 in sputum, bronchoalveolar lavage fluid, airway mucosal biopsies, or exhaled breath condensates (EBC) [11-13]. Moreover, the MMP-9 levels were shown to correlate with severity of disease [14-16].

Although corticosteroids were suggested to influence MMP-9 production [17, 18], the exact mechanism of their action regarding this issue is still unclear. Possibly, corticosteroids may control MMP-9 by direct modulation of its expression $[19,20]$. On the other hand, they are known to attenuate inflammatory response, and thus may also modify the level and activity of MMP-9 in the respiratory tract indirectly [21].

Since the anti-inflammatory action of ICS may be assessed by measurement of local concentrations of selected pro-inflammatory cytokines, e.g. interleukin (IL)-8 and tumor necrosis factor (TNF), we have selected both cytokines as markers of inflammatory reaction [22]. Therefore, the aim of our proof of concept study was to analyze the impact of increased doses of inhaled corticosteroids on the concentration and activity of MMP-9 in exhaled breath condensates of patients with allergic asthma exacerbation. This influence was measured in the context of exhaled nitric oxide (eNO) and two pro-inflammatory cytokines, IL-8 and TNF.

\section{Material and methods}

\section{Patients}

This pilot study involved a very small group of 4 teenager patients (aged 14.0 \pm 3.4 years) with asthma exacerbation, presumably following natural allergen exposure, diagnosed according to GINA guidelines (Global Initiative for Asthma, Strategy for Asthma Diagnosis and Prevention; http:// www.ginasthma.org) [1, 23]. Prior to exacerbation, all patients from the study group were treated using low doses of ICS, which formerly allowed to control symptoms on the satisfactory level [24, 25].

The control group comprised 6 healthy age-matched individuals attending the outpatient clinic for routine control visits.

The concept of the study was reviewed and approved by the local bioethics committee. The study procedures conformed to the ethical guidelines of the World Medical Association Declaration of Helsinki. All patients and their parents gave the informed consent to participate in the study.

\section{Clinical assessment}

All children underwent the routine clinical examination and additional laboratory tests at the recruitment (considered as a baseline). The peripheral blood morphology, analysis of serum total IgE levels and skin tests were done to verify the allergic origin of asthma. The severity of asthma exacerbation was evaluated based on clinical symptoms (shortness of breath, decreased exercise tolerance and wheeze, also occurring in the night), results of spirometric test and the level of exhaled nitric oxide (eNO). The spirometry was performed using Lungtest 1000 (MES, Krakow, Poland). The assessed parameters included forced expiratory volume in the first second $\left(\mathrm{FEV}_{1}\right)$ and the Tiffeneau-Pinelli index. The eNO was measured using Sievers NO 280 equipment (GE Analytical Instruments, Boulder, $\mathrm{CO}$ ).

In addition to routine clinical evaluation and eNO measurement, the exhaled breath condensates were collected using ECoScreen condenser (Jäger, Hoechberg, Germany) [26, 27]. The EBC samples (approx. 700-1000 $\mu$ from each collection) were immediately frozen and maintained at $-70^{\circ} \mathrm{C}$ for further analysis.

\section{Treatment}

The patients with asthma exacerbation have received inhaled corticosteroid (fluticasone propionate) in a daily dose of $500-1000 \mu \mathrm{g}$, with $100 \mu \mathrm{g}$ of long acting $\beta 2$-agonist (salmeterol), twice a day. After 4 weeks of treatment, the clinical assessment, eNO measurement and EBC collection were repeated in the patients group and the results were compared to these from the baseline and to the control group.

\section{Analysis of exhaled breath condensates}

The concentrations of selected cytokines (IL-8 and $\mathrm{TNF}$ ) in breath condensates were measured using Ultrasensitive ELISA sets for human IL-8 and TNF (both from Invitrogen, Camarillo, CA). The tested samples were analyzed using the Microplate Reader 550 (BIO-RAD, Hercules, CA). Based on the respective standard calibration curve, the absorbance of each sample was converted to the concentration of the corresponding cytokine and expressed in pg per $\mathrm{ml}$ of EBC. The assay sensitivity for both cytokines was $0.1 \mathrm{pg} / \mathrm{ml}$.

The total amount of MMP-9 and its actual enzymatic activity in breath condensates were assessed using a novel immunoenzymatic test - QuickZyme Human MMP-9 activity assay (QuickZyme BioSciences, Leiden, Netherlands). The test was done according to the protocol provided by the manufacturer. The absorbance of analyzed samples was measured by Microplate Reader 550 (BIO-RAD) directly after addition of substrate $\left(\mathrm{T}_{0}\right)$ and then after 1 hour of incubation at $37^{\circ} \mathrm{C}\left(\mathrm{T}_{1}\right)$. The MMP-9 concentrations (expressed in $\mathrm{ng} / \mathrm{ml}$ ), both active and total, were calculated based on the standard calibration curve of pre-activated human recombinant MMP-9, with the assay sensitivity of $0.01 \mathrm{ng} / \mathrm{ml}$.

To monitor the possible EBC contamination by MMP-9 from saliva, 5 randomly selected samples were screened for the presence of amylase [28-30].

\section{Results}

When compared to the baseline, after 4 weeks of treatment with increased doses of ICS in all individuals from asthma group we have observed the satisfactory reduc- 


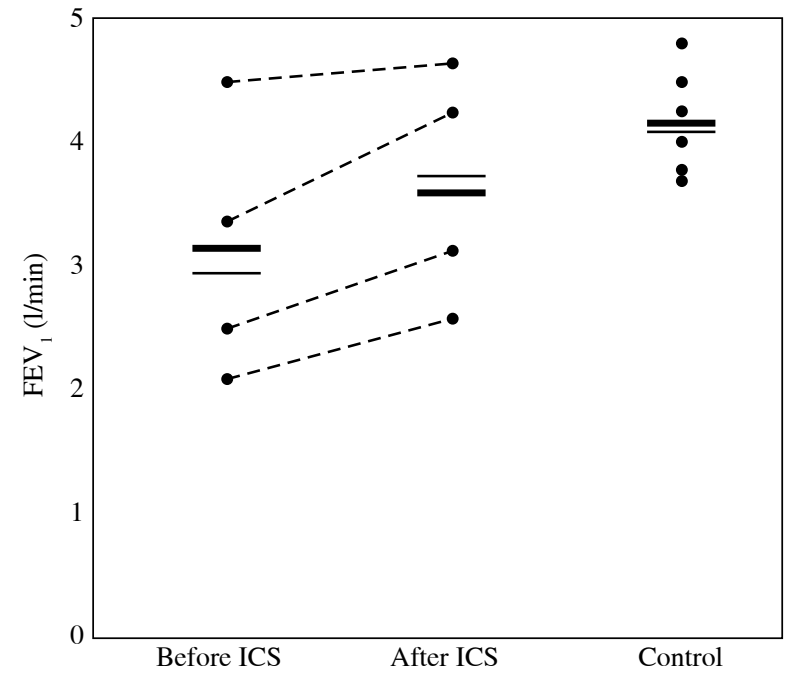

Fig. 1. The results of forced expiratory volume in the first second $\left(\mathrm{FEV}_{1}\right)$ measured in patients with asthma exacerbation (before or after inhaled corticosteroids treatment, respectively) and control individuals. The results were expressed in liters per minute ( $1 / \mathrm{min})$. Each dot represents measurement done in single patient from the respective group. Horizontal lines correspond to mean (bold line) and median (thin line) values for each group. Dashed lines connect respective "before ICS" and "after ICS" values corresponding to their changes following the treatment with inhaled corticosteroids in each patient

tion of clinical symptoms. It included improved exercise tolerance, reduction of breath shortness and significant wheeze relief. Mentioned changes were accompanied by an improvement in patients' spirometric scores, as found in FEV1 measurements (Fig. 1) and Tiffeneau-Pinelli index (Fig. 2). No clinically relevant adverse events, attributed to increased doses of ICS, were observed in the patients group during the study period. Clinical details of patients, results of their blood tests, total $\mathrm{IgE}$ and skin tests are shown in Table 1.

In all patients with asthma exacerbation, the initial eNO levels were higher than in healthy controls (73.0 \pm 30.3 ppb vs. $16.8 \pm 6.6 \mathrm{ppb}$ ). After 4 weeks of intense ICS treatment, in all patients the eNO concentration in exhaled air was apparently lower, as compared to baseline. Nevertheless, the mean eNO level $(26.9 \pm 15.1 \mathrm{ppb})$ still remained higher than in the control group (Fig. 3).

Similarly to eNO, the mean initial concentration of $\mathrm{TNF} / \mathrm{EBC}$ in the asthma group was higher than in healthy controls $(3.5 \pm 1.8 \mathrm{pg} / \mathrm{ml}$ vs. $2.3 \pm 0.9 \mathrm{pg} / \mathrm{ml})$. After 4 weeks of ICS treatment in all patients we have observed a noticeable decrease in TNF/EBC to the mean level of $1.5 \pm 1.0$ pg/ml (Fig. 4).

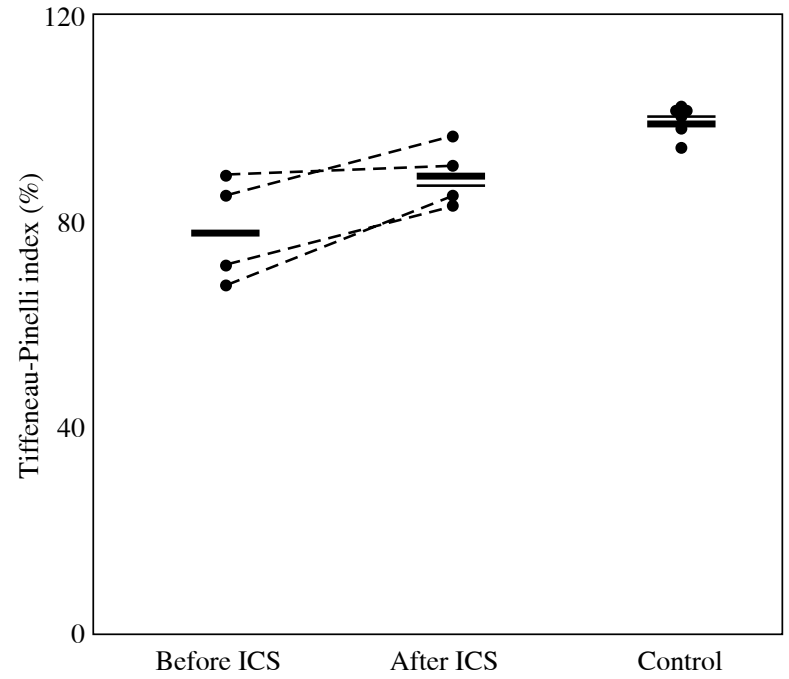

Fig. 2. The results of Tiffeneau-Pinelli index calculated in patients with asthma exacerbation (before or after ICS, respectively) and control individuals. The results of calculation were expressed in percent $(\%)$. Each dot represents results from a single patient in the respective group. Horizontal lines correspond to mean (bold line) and median (thin line) values for each group. Dashed lines connect respective "before ICS" and "after ICS" values corresponding to their changes following the treatment with inhaled corticosteroids in each patient

Table 1. Selected clinical parameters of patients in the asthma and control group

\begin{tabular}{lcc}
\hline Parameter/Patient group & Asthma & $\begin{array}{c}\text { Healthy } \\
\text { control }\end{array}$ \\
\hline Age (years) & $14.0 \pm 3.4$ & $12.9 \pm 3.8$ \\
Sex distribution (male / female) & $3 / 1$ & $4 / 2$ \\
Eosinophil percent (\%) & $8.3 \pm 3.8$ & $1.5 \pm 1.1$ \\
Total IgE (kU/l) & $616.3 \pm 593.9$ & $35.1 \pm 7.4$ \\
Positive skin tests (number of patients) & 4 & 0 \\
Grass pollens & 2 & - \\
Rye pollen & 2 & - \\
Birch pollen & 1 & - \\
Dust mite & 4 & - \\
Cat's dander & 2 & - \\
Alternaria & 2 & - \\
\hline
\end{tabular}

The concentration of IL-8 in both, patients and healthy controls, was below the detection limit (i.e. $<0.1 \mathrm{pg} / \mathrm{ml}$ ) in all EBC samples.

The mean concentration of total MMP-9 in breath condensates was significantly higher in the asthma group than in healthy controls $(12.6 \pm 7.4 \mathrm{pg} / \mathrm{ml}$ vs. $3.6 \pm 1.6 \mathrm{pg} / \mathrm{ml})$. Noteworthy, after 4 weeks with increased doses of ICS, the mean MMP-9/EBC concentration in treated patients 


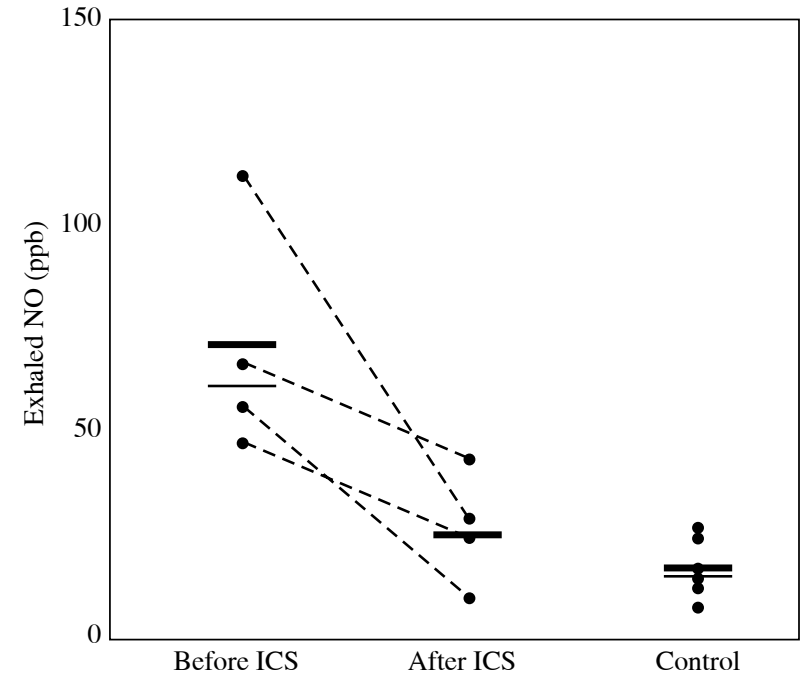

Fig. 3. The results of exhaled nitric oxide (eNO) assessed in patients with asthma exacerbation (before or after ICS, respectively) and control individuals. The results were expressed in particles per billion (ppb). Each dot represents measurement done in a single patient from the respective group. Horizontal lines correspond to mean (bold line) and median (thin line) values for each group. Dashed lines connect respective "before ICS" and "after ICS" values corresponding to their changes following the treatment with inhaled corticosteroids in each patient

did not change significantly $(12.6 \pm 7.4 \mathrm{pg} / \mathrm{ml}$ to $14.0 \pm 5.9$ $\mathrm{pg} / \mathrm{ml})$. Interestingly, although in one patient the concentration of total MMP-9/EBC increased considerably, nevertheless in three other individuals it remained on the baseline level (Fig. 5). The analysis in respect of actual activity of MMP-9 in breath condensates has shown that the calculated levels of its active fraction corresponded to approximately $70-80 \%$ of total MMP-9 concentration. However, the same trend, as for total MMP-9, was observed in case of active MMP-9 regarding its concentration changes in course of intense ICS treatment (data not shown).

None of tested EBC samples has shown any detectable amounts of amylase.

\section{Discussion}

Inhaled corticosteroids are the key component in standard treatment of patients with asthma [2, 31, 32]. Numerous studies have proven that ICS, when used in asthma exacerbation, effectively reduced clinical symptoms and decreased selected markers of inflammation [4, 33-36]. Furthermore, some authors have demonstrated that ICS treatment in patients with asthma resulted in a decrease in MMP-9 amount in sputum or in mucosal biopsy [17, 18].

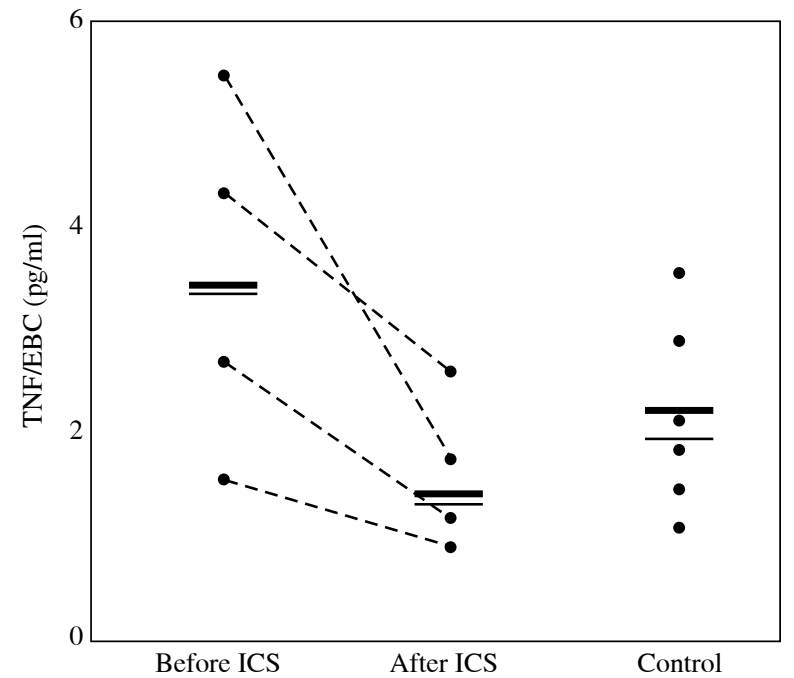

Fig. 4. The results of measurement of TNF concentration in exhaled breath condensate (TNF/EBC) in patients with asthma exacerbation (before or after ICS, respectively) and control individuals. The results were expressed in picograms per milliliter (pg/ml). Each dot represents measurement done in a single patient from the respective group. Horizontal lines correspond to mean (bold line) and median (thin line) values for each group. Dashed lines connect respective "before ICS" and "after ICS" values corresponding to their changes following the treatment with inhaled corticosteroids in each patient

Surprisingly, in our proof of concept study even high doses of ICS, despite their apparent beneficial effect in reduction of clinical symptoms and significant anti-inflammatory potential, did not reduce the concentration and activity of MMP-9 in exhaled breath condensates. Moreover, in contrast to other report [15], we did not observe any correlation between occurrence of clinical symptoms or their change, and the concentration of MMP-9/EBC in ICS-treated patients.

Several reasons of observed inconsistency could be taken into consideration. Undoubtedly, the main limitation of our proof of concept study is a very small group of patients. Regardless of the noticeable trend, our observation could not be considered as statistically significant and should obviously be verified in a larger group of patients. On the other hand, even despite such small study group we have seen a pronounced effect of ICS treatment on reduction of asthma exacerbation symptoms. The observed reduction of breath shortness and wheezing, or improvement of exercise tolerance after increased doses of ICS correlated with improvement in results of spirometric tests - $\mathrm{FEV}_{1}$ and Tiffeneau-Pinelli index. Noticeably, in laboratory assessments this improvement was clearly associated with a marked decrease in eNO and TNF/EBC levels, but not MMP-9. 
Another explanation for observed discrepancies between previously mentioned studies and our data could be various sample sources and different detection systems. In our study, instead of mucosal biopsy or induced sputum, as a material for MMP-9 measurement we have used exhaled breath condensate. This method, due to its non-invasiveness, allows the repetitive sample collection, even in very young children $[37,38]$. Moreover, it does not require any anesthesia, which may interfere with results of biochemical assessment [39]. The induced sputum, although easily accessible in the majority of adults, may be more problematic in young patients. Besides, sputum contains huge quantities of MMP-9 produced by salivary glands [29, 30], which significantly limit reliable assessment of this enzyme, at least in the context of its possible involvement in airway pathologies. Hence, particularly for the assessment of MMP-9, the composition of saliva-free EBC seems to better reflect the current pathological state of the entire respiratory tract [27].

Furthermore, in contrast to previously mentioned reports, which exploited simple assessment of MMP-9 protein by ELISA, in our pilot study we have used a novel immunoenzymatic method, based on colorimetric measurement of MMP- 9 activity. Therefore, our results may reproduce the actual in vivo activity of this enzyme more precisely than standard ELISA.

Last but not least, the discrepancies between our data and mentioned reports may be explained by a significant difference in the observation period. In contrast to one-year observation by Wang et al. [17], our study could possibly be too short to see long-term effects of ICS. However, most recently it has been demonstrated that even prolonged ICS administration, despite good clinical control of asthma symptoms, did not normalize elevated MMP-9 in EBC [40].

Based on observations concerning the decrease in eNO and TNF/EBC, but not MMP-9/EBC, in response to increased doses of ICS, one can speculate that the level of MMP-9 in EBC appears to be independent from eventual inflammatory response. Since inflammatory leukocytes, especially macrophages and neutrophils, are considered as main producers of MMP-9 [41], there arises the question concerning alternative sources of this metalloproteinase. Several candidates have been suggested so far, including respiratory tract epithelium, mucosal mast cells, fibroblasts as well as smooth muscle cells from airway mucosa [42-45]. Such variety of possible MMP-9 producers may explain the relatively weak or even lack of response to ICS treatment as regards production and activity of this enzyme.

It is plausible that ICS, although effective in reduction of symptoms and inflammatory response in asthma exacerbation, may be not sufficient to fully control the course of disease. Moreover, some authors even suggested that ICS do not protect from long-term structural and functional alterations of the respiratory tract, which are referred to as airway remodeling $[46,47]$. This assumption may be crucial as regards widespread ICS use in asthma treatment.

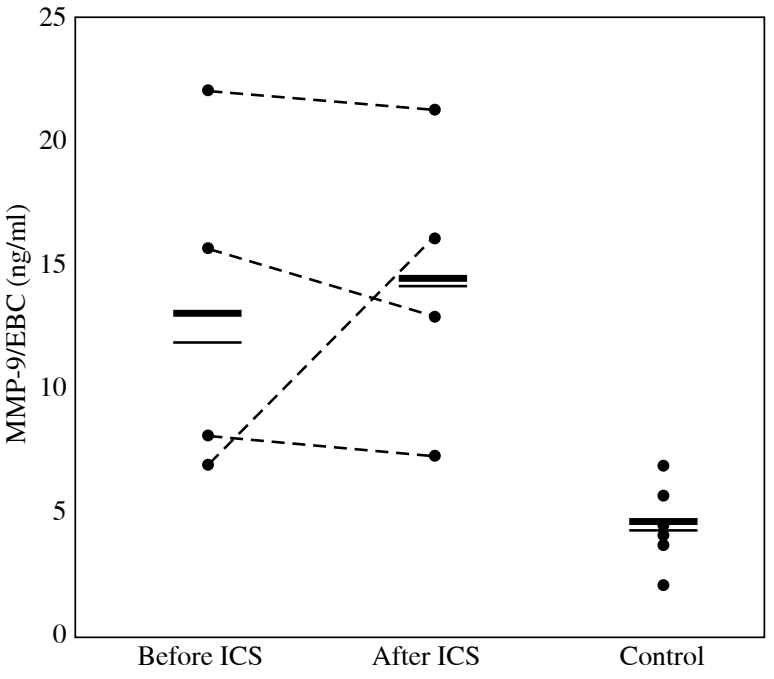

Fig. 5. The results of assessment of total MMP-9 concentration in exhaled breath condensate (MMP-9/EBC) in patients with asthma exacerbation (before or after ICS, respectively) and control individuals. The concentration of total MMP-9 was extrapolated from results of measurement of proteolytic activity in organomercurial-pre-activated samples, and expressed in nanograms per milliliter (ng/ml). Each dot represents measurement done in a single patient from the respective group. Horizontal lines correspond to mean (bold line) and median (thin line) values for each group. Dashed lines connect respective "before ICS" and "after ICS" values corresponding to their changes following the treatment with inhaled corticosteroids in each patient

On the other hand, such uncertainty may be especially important due to a postulated pivotal role of MMP-9 in airway remodeling in asthma [48]. However, the exact role of MMP-9 in airway remodeling still remains unclear. Numerous authors claim that high levels of MMP-9 may destroy ECM in airway mucosa. This damage could stimulate chaotic tissue regeneration, which may result in increased fibrosis and, thus, it would determine a detrimental effect of MMP-9 on disease progression [49, 50]. The enthusiasts of the opposite concept suggest that MMP-9 may digest improperly deposited ECM components, and thus it actually might play a protective role against tissue fibrosis and airway remodeling [51]. Therefore, since being critical for the basic strategy of asthma treatment, this issue requires urgent and univocal explanation.

The authors declare no conflict of interest.

The study was supported by the individual research grants of the Medical University of Warsaw. 


\section{References}

1. Boulet LP, FitzGerald JM, Reddel HK (2015): The revised 2014 GINA strategy report: opportunities for change. Curr Opin Pulm Med 21: 1-7.

2. Chong J, Haran C, Chauhan BF, Asher I (2015): Intermittent inhaled corticosteroid therapy versus placebo for persistent asthma in children and adults. Cochrane Database Syst Rev CD011032.

3. Razi CH, Akelma AZ, Harmanci K, et al. (2015): The addition of inhaled budesonide to standard therapy shortens the length of stay in hospital for asthmatic preschool children: a randomized, double-blind, placebo-controlled trial. Int Arch Allergy Immunol 166: 297-303.

4. Zhao Y, Han S, Shang J, et al. (2015): Effectiveness of drug treatment strategies to prevent asthma exacerbations and increase symptom-free days in asthmatic children: a network meta-analysis. J Asthma 52:846-857.

5. Jeffery PK (2001): Remodeling in asthma and chronic obstructive lung disease. Am J Respir Crit Care Med 164: S28-S38.

6. Chetta A, Zanini A, Foresi A, et al. (2003): Vascular component of airway remodeling in asthma is reduced by high dose of fluticasone. Am J Respir Crit Care Med 167: 751-757.

7. Atkinson JJ, Senior RM (2003): Matrix metalloproteinase-9 in lung remodeling. Am J Respir Cell Mol Biol 28: 12-24.

8. Salib RJ, Howarth PH (2003): Remodelling of the upper airways in allergic rhinitis: is it a feature of the disease? Clin Exp Allergy 33: 1629-1633.

9. Sohal SS, Soltani A, Reid D, et al. (2014): A randomized controlled trial of inhaled corticosteroids (ICS) on markers of epithelial-mesenchymal transition (EMT) in large airway samples in COPD: an exploratory proof of concept study. Int J Chron Obstruct Pulmon Dis 9: 533-542.

10. Lee YC, Lee HB, Rhee YK, Song CH (2001): The involvement of matrix metalloproteinase-9 in airway inflammation of patients with acute asthma. Clin Exp Allergy 31: 1623-1630.

11. Cataldo DD, Bettiol J, Noel A, et al. (2002): Matrix metalloproteinase-9, but not tissue inhibitor of matrix metalloproteinase-1, increases in the sputum from allergic asthmatic patients after allergen challenge. Chest 122: 1553-1559.

12. Erlewyn-Lajeunesse M, Hunt L, Pohunek P, et al. (2008): Bronchoalveolar lavage MMP-9 and TIMP-1 in preschool wheezers and their relationship to persistent wheeze. Pediatr Res 64: 194-199.

13. Barbaro MP, Spanevello A, Palladino GP, et al. (2014): Exhaled matrix metalloproteinase-9 (MMP-9) in different biological phenotypes of asthma. Eur J Intern Med 25: 92-96.

14. Belleguic C, Corbel M, Germain N, et al. (2002): Increased release of matrix metalloproteinase- 9 in the plasma of acute severe asthmatic patients. Clin Exp Allergy 32: 217-223.

15. Karakoc GB, Yukselen A, Yilmaz M, et al. (2012): Exhaled breath condensate MMP-9 level and its relationship with asthma severity and interleukin-4/10 levels in children. Ann Allergy Asthma Immunol 108: 300-304.

16. Mattos W, Lim S, Russell R, et al. (2002): Matrix metalloproteinase-9 expression in asthma. Effect of asthma severity, allergen challenge and inhaled corticosteroids. Chest 122: 15431552.

17. Wang K, Liu CT, Wu YH, et al. (2011): Effects of formoterol-budesonide on airway remodeling in patients with moderate asthma. Acta Pharmacol Sin 32: 126-132.

18. Weitoft M, Andersson C, Andersson-Sjöland A, et al. (2014): Controlled and uncontrolled asthma display distinct alveolar tissue matrix compositions. Respir Res 15: 67.
19. De Paiva CS, Corrales RM, Villarreal AL, et al. (2006): Corticosteroid and doxycycline suppress MMP-9 and inflammatory cytokine expression, MAPK activation in the corneal epithelium in experimental dry eye. Exp Eye Res 83: 526-535.

20. Gilet A, Zou F, Boumenir M, et al. (2015): Aldosterone up-regulates MMP-9 and MMP-9/NGAL expression in human neutrophils through p38, ERK1/2 and PI3K pathways. Exp Cell Res 331: 152-163.

21. Wang C, Lou H, Wang X, et al. (2015): Effect of budesonide transnasal nebulization in patients with eosinophilic chronic rhinosinusitis with nasal polyps. J Allergy Clin Immunol 135: 922-929.e6.

22. Broide DH (2008): Immunologic and inflammatory mechanisms that drive asthma progression to remodeling. J Allergy Clin Immunol 121: 560-572.

23. Kroegel C (2009): Global Initiative for Asthma (GINA) guidelines: 15 years of application. Expert Rev Clin Immunol 5: 239-249.

24. Akturk H, Karakoc-Aydiner E, Ozen A, et al. (2015): Predictive risk factors for relapse after cessation of inhaled corticosteroids in well-controlled childhood asthma. Minerva Pediatr [Epub ahead of print]

25. Braido F, Baiardini I, Blasi F, et al. (2015): Adherence to asthma treatments: 'we know, we intend, we advocate'. Curr Opin Allergy Clin Immunol 15: 49-55.

26. Zagorska W, Grzela K, Kulus M, et al. (2013): Increased cys-leukotrienes in exhaled breath condensate and decrease of PNIF after intranasal allergen challenge support the recognition of allergic rhinitis in children. Arch Immunol Ther Exp 61: 327-332.

27. Zagorska W, Grzela K, Kulus M, et al. (2014): Nitric oxide, IL-6 and IL-13 are increased in the exhaled breath condensates of children with allergic rhinitis. Acta Paediatr 103: e148-e153.

28. Gaber F, Acevedo F, Delin I, et al. (2006): Saliva is one likely source of leukotriene B4 in exhaled breath condensate. Eur Respir J 28: 1229-1235.

29. Labat C, Temmar M, Nagy E, et al. (2013): Inflammatory mediators in saliva associated with arterial stiffness and subclinical atherosclerosis. J Hypertens 31: 2251-2258.

30. Nędzi-Góra M, Kostrzewa-Janicka J, Górska R (2014): Elastase and metalloproteinase-9 concentrations in saliva in patients with chronic periodontitis. Cent Eur J Immunol 39: 357-364.

31. Domínguez-Ortega J, Phillips-Anglés E, Barranco P, Quirce S (2015): Cost-effectiveness of asthma therapy: a comprehensive review. J Asthma 52: 529-537.

32. Rodriguez-Martinez CE, Nino G, Castro-Rodriguez JA (2015): Cost-utility analysis of daily versus intermittent inhaled corticosteroids in mildpersistent asthma. Pediatr Pulmonol 50: 735-746.

33. Hayes CE, Nuss HJ, Tseng TS, Moody-Thomas S (2015): Use of asthma control indicators in measuring inhaled corticosteroid effectiveness in asthmatic smokers: a systematic review. J Asthma 29: 1-10.

34. Hilvering B, Pavord ID (2015): What goes up must come down: biomarkers and novel biologicals in severe asthma. Clin Exp Allergy 45: 1162-1169.

35. Woodruff PG, Boushey HA, Dolganov GM, et al. (2007): Genome-wide profiling identifies epithelial cell genes associated with asthma and with treatment response to corticosteroids. Proc Natl Acad Sci USA 104: 15858-15863.

36. Kelly MM, King EM, Rider CF, et al. (2012): Corticosteroid-induced gene expression in allergen-challenged asthmatic 
subjects taking inhaled budesonide. Br J Pharmacol 165: 1737 1747.

37. Griese M, Latzin P, Beck J (2001): A noninvasive method to collect nasally exhaled air condensate in humans of all ages. Eur J Clin Invest 31: 915-920.

38. Rosias PP, Robroeks CM, van de Kant KD, et al. (2010); Feasibility of a new method to collect exhaled breath condensate in pre-school children. Pediatr Allergy Immunol 21: e235-e244.

39. Li Q, Zhang L, Han Y, Jiang Z, Wang Q (2012): Propofol reduces MMPs expression by inhibiting NF- $\mathrm{kB}$ activity in human MDA-MB-231 cells. Biomed Pharmacother 66: 52-56.

40. Grzela K, Zagorska W, Krejner A, et al. (2015): Prolonged treatment with inhaled corticosteroids does not normalize high activity of matrix metalloproteinase- 9 in exhaled breath condensates of children with asthma. Arch Immunol Ther Exp 63: 231-237.

41. Mautino G, Oliver N, Chanez P, et al. (1997): Increased release of matrix metalloproteinase-9 in bronchoalveolar lavage fluid and by alveolar macrophages of asthmatics. Am J Respir Cell Mol Biol 17: 583-591.

42. Kimata M, Ishizaki M, Tanaka H, et al. (2006): Production of matrix metalloproteinases in human cultured mast cells: involvement of protein kinase $\mathrm{C}$-mitogen activated protein kinase kinase extracellular signal-regulated kinase pathway. Allergol Int 55: 67-76.

43. Maxova H, Bacakova L, Lisa V, et al. (2010): Production of proteolytic enzymes in mast cells, fibroblasts, vascular smooth muscle and endothelial cells cultivated under normoxic or hypoxic conditions. Physiol Res 59: 711-719.

44. Abel M, Vliagoftis H (2008): Mast cell-fibroblast interactions induce matrix metalloproteinase-9 release from fibroblasts: role for IgE-mediated mast cell activation. J Immunol 180: 35433550.

45. Roth M, Zhong J, Zumkeller C, et al. (2013): The role of IgE-receptors in IgE-dependent airway smooth muscle cell remodelling. PLoS ONE 8: e56015.

46. Bisgaard H, Hermansen MN, Loland L, et al. (2006): Intermittent inhaled corticosteroids in infants with episodic wheezing. N Engl J Med 354: 1998-2005.

47. Guilbert TW, Morgan WJ, Zeiger RS, et al. (2006): Long-term inhaled corticosteroids in preschool children at high risk for asthma. N Engl J Med 354: 1985-1997.

48. Grzela K, Litwiniuk M, Zagorska W, Grzela T (2016): Airway Remodeling in Chronic Obstructive Pulmonary Disease and Asthma: the Role of Matrix Metalloproteinase-9. Arch Immunol Ther Exp 64: 47-55.

49. Ko FW, Diba C, Roth M, et al. (2005): A comparison of airway and serum matrix metalloproteinase-9 activity among normal subjects, asthmatic patients, and patients with asthmatic mucus hypersecretion. Chest 127: 1919-1927.

50. Liu CP, Hsieh CH, Wu BN, et al. (2012): Inhaled KMUP-1 Prevents Allergic Pulmonary Vascular Inflammation and Remodeling via NO and Suppressed MMP-9 and ICAM-1/ VCAM-1. Inflamm Allergy Drug Targets 11: 251-261.

51. Royce SG, Shen M, Patel KP, et al. (2015): Mesenchymal stem cells and serelaxin synergistically abrogate established airway fibrosis in an experimental model of chronic allergic airways disease. Stem Cell Res 15: 495-505. 